\title{
Procedures performed by general practitioners and general internal medicine physicians - a comparison based on routine data from Northern Germany
}

\author{
C. Strumann ${ }^{*^{*}}$ D, K. Flägel ${ }^{1}$, T. Emcke ${ }^{2}$ and J. Steinhäuser ${ }^{1}$
}

\begin{abstract}
Background: In response to a rising shortage of general practitioners (GPs), physicians in general internal medicine (GIM) have become part of the German primary care physician workforce. Previous studies have shown substantial differences in practice patterns between both specialties. The aim of this study was to analyse and compare the application of procedures by German GPs and GIM physicians based on routine data.

Methods: The Association of Statutory Health Insurance Physicians in the federal state Schleswig-Holstein (Northern Germany) provided invoicing data of the first quarters of 2013 and 2015. Differences between GPs and GIM physicians in the implementation rate of 46 selected primary care procedures were examined by means of the Pearson $x^{2}$-test. The selection of procedures was based on international and own preliminary studies on primary care procedures.

Results: In the first quarter of 2013/2015 respectively, 1228/1227 GPs and 447/484 GIM physicians provided services in Schleswig-Holstein. Significant differences were found for 20 of the 46 procedures. GPs had higher application rates of procedures concerning health screening (e.g. adolescent health examination, well-child visits) and minor surgery. GIM physicians more often applied technology-oriented procedures, such as ultrasound scans, electrocardiograms (ECG), and 24-h ambulatory blood pressure measurements. The treatment patterns of both specialities did not vary much during the study period. Cardiac stress testing was the only significantly increased GP procedure in that time.

Conclusions: Our results suggest substantial differences in the application of procedures between GPs and GIM physicians with potential consequences for the overall primary healthcare provision. The findings could foster a discussion about training needs for procedures in primary care to ensure its comprehensiveness. The results reflect scope for changes in vocational training in the future for an effective and efficient re-allocation of primary healthcare.
\end{abstract}

Keywords: Procedural skills, Primary care, General internal medicine, General practitioner

\section{Background}

In most industrialised countries, the demand for healthcare is increasing due to an ageing population coinciding with a declining number of primary care physicians [1-3]. Primary care physicians are general practitioners (GPs), physicians in general internal medicine (GIM) or paediatricians who provide "care for the undifferentiated patient at the point of first contact" [4]. The range of services that

\footnotetext{
* Correspondence: c.strumann@uni-luebeck.de

${ }^{1}$ Institute of Family Medicine, University Hospital Schleswig-Holstein, Campus Luebeck, Ratzeburger Allee 160, 23538 Luebeck, Germany

Full list of author information is available at the end of the article
}

primary care patients require is extensive [5]. However, according to previous studies, procedures differ considerably between GPs and GIM physicians, e.g. regarding the use of diagnostics [6], medical charges [7], prescribing [8], communication [9], provision of care for patients with common conditions [10], range of specific health needs covered [11] and patient outcomes [12].

In Germany, most primary care physicians are traditionally self-employed. However, they need an accreditation for service provision for patients within the statutory health insurance scheme that covers about $90 \%$ of the population. In 2016, around 79\% of the German

(c) The Author(s). 2018 Open Access This article is distributed under the terms of the Creative Commons Attribution 4.0 International License (http://creativecommons.org/licenses/by/4.0/), which permits unrestricted use, distribution, and reproduction in any medium, provided you give appropriate credit to the original author(s) and the source, provide a link to the Creative Commons license, and indicate if changes were made. The Creative Commons Public Domain Dedication waiver (http://creativecommons.org/publicdomain/zero/1.0/) applies to the data made available in this article, unless otherwise stated. 
population visited a primary care physician at least once [13]. The distribution of physicians is regulated and allocated by the Association of Statutory Health Insurance Physicians (ASHIP), which is responsible for the accreditation process to maintain a sufficient and high-quality supply of physicians [14].

Whereas the international definition of primary care physicians includes paediatricians, the definition by the German ASHIP does not, so that the primary care physician workforce in Germany only consists of GPs and GIM physicians. By law, GPs are preferred in the accreditation process [15]. However, the declining number of GPs in the last decade has resulted in local shortages, especially in rural areas $[16,17]$. In response to the rising shortage of GPs, a rise in the quota of GIM physicians providing primary care can be observed [18].

A previous study using self-assessment of GPs and GIM physicians [19] showed differences in the application of medical procedures and suggested implications for the quality and safety of primary care provision in Germany. In general, the use of survey data based on self-assessment can be problematic because of selection or response biases [20]. Influences on self-assessment such as gender, age, emotional status and recall bias have been described [21-24]. Moreover, studies based on survey data are prone to selection bias [25]. In contrast, routine data present a reliable source of information that avoid selection or recall bias [26, 27]. Findings of studies based on survey data can be crosschecked by analysing routine data.

The aim of this study was to analyse and compare, based on routine data, the application of procedures by German GPs and GIM physicians. The results may subsequently allow to deduce measures to promote an effective and efficient re-allocation of primary healthcare resources.

\section{Methods}

This study is based on the analysis of routine data from the ASHIP of the federal state Schleswig-Holstein located in Northern Germany. The concentration on a specific federal state of Germany allows to reduce practice variations based on regional differences and state-specific regulations [28].

\section{Data selection}

Based on a previously consented questionnaire comprising relevant procedures in German primary care $[19,25]$ the research team checked the doctor's fee scale 2015 [29] for codes addressing procedures or at least comprising procedures of the questionnaire. Both the routine data provided by the ASHIP and the data collected by the questionnaire refer to the first three months of the years 2013 and 2015 respectively. Data included the number of all billed codes of the doctor's fee scale by all GPs and GIM physicians in the federal state of Schleswig-Holstein. The analysis concentrated on codes reflecting services with high relevance in primary care [30-33]. Procedures were defined as discrete, diagnostic or therapeutic activities requiring knowledge and manual skills, performed on patients following the definition of Sylvester et al. [31]. Out of 90 possible physicians' procedures listed in the initial questionnaire [19, 25], 46 were identified that could be employed by both GPs and GIM physicians. Table 1 shows the codes for services and whether the respective procedure is part of the training curriculum of the respective specialty.

\section{Statistical analysis}

Differences in the application of a specific procedure by GPs and GIM physicians as well as differences between the two study periods were analysed by means of the Pearson $x^{2}$-test. All tests of significance were two-tailed and were corrected using the Bonferroni method to counteract the problem of multiple comparisons [34]. A $p$-value $<0.05$ was considered as statistically significant. Statistical analyses were performed with MATLAB software, version 9.4 (R2018a) (The MathWorks, Natick, MA, USA).

\section{Results}

In the first quarter of 2013, 1228 GPs and 447 GIM physicians provided services in Schleswig-Holstein. In 2015, the number of GPs remained unchanged (1227), while the number of GIM physicians had increased to 484 . There are no substantial differences between the number of distinct fee scale codes submitted by GPs and GIM physicians. For both specialities the overall number of services invoiced and the physicians' average of services invoiced have increased over the time frame by $37.7 \%$ and $27.2 \%$, respectively. The percentages of the total number of codes reflecting the selected procedures are relatively small and have declined slightly over the study period (2015: 2\% (GP) and 2.7\% (GIM)). Table 2 shows the number of physicians, the number of distinct service codes, the total number of codes invoiced and other statistics for both years and specialties.

There are several significant differences between GIM physicians and GPs with regard to the application of specific procedures. Of note are the higher GP figures for health screening services, especially adolescent health examination and well-child visits. The number of minor surgery procedures performed by GPs is also significantly higher. These include primary and secondary wound healing, excisions, treatment of ingrown toenails and phlebotomy. Procedures performed to a higher extent by GMI physicians are in general based on more technical approaches, i.e. services using ultrasound diagnostics 
Table 1 Assignment of the procedures to the bill codes

\begin{tabular}{|c|c|}
\hline Code & Bill code description [29] \\
\hline \multicolumn{2}{|c|}{ Well-child visit } \\
\hline 01712 & Well-child visit of the new-born during the 3rd to 10th day of \\
\hline 01713 & Well-child visit during the 4 th and 5th week of life "(U3)" \\
\hline 01714 & Well-child visit during the 3rd and 4th month of life "(U4)" \\
\hline 01715 & Well-child visit during the 6th and 8th month of life "(U5)" \\
\hline 01716 & Well-child visit during the 10th and 12th month of life "(U6)" \\
\hline 01717 & Well-child visit during the 21st to 24th month of life "(U7)" \\
\hline 01718 & Well-child visit during the 46th to 48th month of life "(U8)" \\
\hline 01719 & Well-child visit during the 60th to 64th month of life "(U9)" \\
\hline 01723 & Well-child visit during the 36th to 43rd month of life "(U7a)" \\
\hline 1720 & Adolescent health examination "(I1)" \\
\hline
\end{tabular}

Procedure [25]

Part of training [45]

GP GIM

Minor surgery

02301 Minor surgery II: primary wound closure with sutures thrombotic syndrome, superficial and deep vein thrombosis and/or lymphoedema

Injection and infusion

02101 Infusion

02321 Suprapubic catheter insertion

02323 Transurethral catheter insertion

Paracentesis and insertion

02340 Paracentesis

02343 Trephination of pleural cavity and non-surgical pleural drainage

Treatment of musculoskeletal disorders

02360 Treatment under local anaesthesia

31,910 Reduction of carpal or tarsal dislocation (distal)

31,912 Reduction of dislocated cubital or knee joint (distal)

31,914 Reduction of dislocated cubital or knee joint (proximal)
Adolescent health examination

Surgical suture

Drainage of acute paronychia

Electrocautery of skin lesion

I\&D of an abscess

I\&D of a perianal abscess

Glueing of a wound

Removal of foreign object

Excision of lipoma

Partial removal of toenail

Wound debridement

Compression therapy

Infusion

yes yes

Suprapubic catheter insertion yes yes

Transurethral catheter insertion yes yes

Ascites paracentesis yes yes

Trepination of subungual haematoma yes no

Paracentesis of knee joint yes yes

Paracentesis of scapula joint yes yes

Thoracentesis yes yes

Trepination of tension pneumothorax yes yes

Chest tube insertion yes yes

Neural therapy yes no

Reduction of dislocated finger no no

Reduction of displaced fracture of the radial head no ${ }^{a}$ no

Reduction of dislocated shoulder joint no 
Table 1 Assignment of the procedures to the bill codes (Continued)

\begin{tabular}{|c|c|c|c|c|}
\hline \multirow[t]{2}{*}{ Code } & \multirow[t]{2}{*}{ Bill code description [29] } & \multirow[t]{2}{*}{ Procedure [25] } & \multicolumn{2}{|c|}{ Part of training [45] } \\
\hline & & & GP & GIM \\
\hline \multicolumn{5}{|c|}{ Instrument-based procedures } \\
\hline 02500 & Single inhalation therapy & Preparing a nebulizer for antiobstructive therapy & no & no \\
\hline 03321 & Cardiac stress test & Cardiac stress test & yes & yes \\
\hline 03324 & 24-h ambulatory blood pressure monitoring & 24-h ambulatory blood pressure monitoring & yes & yes \\
\hline 03330 & Spirometry & Spirometry & yes & yes \\
\hline 03331 & Proctoscopy & Proctoscopy & yes & yes \\
\hline 03335 & $\begin{array}{l}\text { Exploratory audiometry after previously documented, hearing } \\
\text { test anomalies }\end{array}$ & Diagnostic audiometer test & no & no \\
\hline 33012 & Thyroid sonography B-scan & Thyroid sonography thyroid & yes & yes \\
\hline 33042 & Abdominal sonography B-scan & Abdominal sonography & yes & yes \\
\hline 33060 & $\begin{array}{l}\text { Sonographic examination of extracranial cerebral vessels, the } \\
\text { periorbital arteries, subclavian arteries and vertebral arteries by } \\
\text { CW-Doppler }\end{array}$ & Doppler ultrasound of brain-supplying vessels & yes & yes \\
\hline 33061 & $\begin{array}{l}\text { CW Doppler sonography of limb blood vessels, at least } 3 \\
\text { transducer locations per limb }\end{array}$ & Compression sonography of lower extremities & yes & yes \\
\hline 33076 & Limb vein B-scan sonography at least 8 transducer locations & & & \\
\hline \multicolumn{5}{|c|}{ Laboratory diagnostic procedures } \\
\hline 32031 & Microscopic urinalysis for morphological components & Microscopic urinalysis & yes & yes \\
\hline 32040 & Faecal occult blood test in 3 samples & Faecal occult blood test & yes & yes \\
\hline 01734 & $\begin{array}{l}\text { Examination for faecal occult blood according to stage } \\
\text { D.-III of the early detection of cancer-guideline, including costs }\end{array}$ & & & \\
\hline 32045 & microscopic examination of bodily material & Examine a native sample for funghi & yes & yes \\
\hline \multicolumn{5}{|c|}{ Emergency medicine } \\
\hline 01220 & Resuscitation & Mask ventilation & yes & yes \\
\hline 01221 & $\begin{array}{l}\text { Supplement to Resuscitation (Coniotomy and / or } \\
\text { Endotracheal Intubation) }\end{array}$ & Endotracheal intubation & yes & yes \\
\hline 01222 & Supplement to Resuscitation (defibrillation) & Defibrillation & yes & yes \\
\hline \multicolumn{5}{|c|}{ Gynaecology } \\
\hline 01830 & Insertion of intrauterine device & insertion of intrauterine device & no & no \\
\hline 01730 & Cancer screening for women & Gynaecological examination & no & no \\
\hline 01825 & Cervical smear test & Cervical smear test & no & no \\
\hline
\end{tabular}

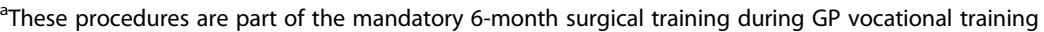

Table 2 Descriptive Statistics

\begin{tabular}{|c|c|c|c|c|c|c|}
\hline \multirow{2}{*}{$\begin{array}{l}\text { year } \\
\text { specialty }\end{array}$} & \multicolumn{2}{|l|}{2013} & \multicolumn{2}{|l|}{2015} & \multicolumn{2}{|c|}{ change (in \%) } \\
\hline & GP & GIM & GP & GIM & GP & GIM \\
\hline physicians & 1228 & 447 & 1227 & 484 & -0.1 & 8.3 \\
\hline number of fee scale codes invoiced & 697 & 613 & 683 & 675 & -2.0 & 10.1 \\
\hline total number of codes invoiced by all physicians & $6,752,667$ & $2,499,625$ & $8,856,848$ & $3,442,080$ & 31.2 & 37.7 \\
\hline total number of codes invoiced per physician & 5498.9 & 5592.0 & 7218.3 & 7111.7 & 31.3 & 27.2 \\
\hline total number of codes invoiced by all physicians reflecting selected procedures & 179,095 & 85,413 & 180,779 & 93,286 & 0.9 & 9.2 \\
\hline percentage of the total number of codes reflecting selected procedures (in \%) & 2.7 & 3.4 & 2.0 & 2.7 & -23.0 & -20.7 \\
\hline
\end{tabular}


or an electrocardiogram (ECG). Another service that is significantly more frequently performed by GIM physicians than GPs is the long-term blood pressure measurement. In general, the treatment patterns of both specialties did not vary much over the time frame. Cardiac stress testing was the only procedure by GPs that saw an increase in the study period. The proportions of GPs and GIM physicians performing a specific procedure in the study periods of 2013 and 2015 are shown in Tables 3 and 4 with the respective $p$-values for group differences. For ease of illustration, procedures which were applied by less than $1 \%$ of physicians are not shown.

\section{Discussion}

The comprehensiveness of general practice in the provision of primary healthcare [35] and its coordinating role in referring patients across the individual healthcare sectors $[36,37]$ determine the strength of primary care, since both factors have positive effects on health outcomes, equality and overall efficiency in healthcare systems [38-43]. Therefore, GPs traditionally received training focusing on treating the whole person through all stages of life [44]. The curriculum of GPs in Schleswig-Holstein includes working in primary care, i.e. private practices for at least 24 months. In contrast, the training of internal medicine physicians happens entirely in the hospital setting [45].

Table 3 Application rates of general practitioners (GPS) and general internal medicine (GIM) physicians for procedures performed to a greater extent by GPs (in \%)

\begin{tabular}{|c|c|c|c|c|c|c|c|}
\hline \multirow[t]{2}{*}{ Code } & \multirow[t]{2}{*}{ Description } & \multicolumn{3}{|l|}{2013} & \multicolumn{3}{|l|}{2015} \\
\hline & & $\mathrm{GP}(n=1228)$ & $\mathrm{GIM}(n=447)$ & $p$-value* & $\mathrm{GP}(n=1227)$ & $\mathrm{GIM}(n=484)$ & $p$-value* \\
\hline 02310 & $\begin{array}{l}\text { Secondary healing wound care and/or decubital } \\
\text { ulcer care }\end{array}$ & 60.4 & 43.6 & $<0.001$ & 64.6 & 44.0 & $<0.001$ \\
\hline 02301 & $\begin{array}{l}\text { Minor surgery II: primary wound closure with } \\
\text { sutures }\end{array}$ & 39.0 & 13.4 & $<0.001$ & 37.8 & 16.7 & $<0.001$ \\
\hline 01734 & $\begin{array}{l}\text { Examination for faecal occult blood according } \\
\text { to stage D.-III of the early detection of cancer- } \\
\text { guideline, including costs }\end{array}$ & 27.2 & 22.1 & n.s. & 27.9 & 24.8 & n.s. \\
\hline 01720 & Adolescent health examination "(J1)" & 27.1 & 13.9 & $<0.001$ & 25.5 & 9.5 & $<0.001$ \\
\hline 02312 & $\begin{array}{l}\text { Treatment of single or multiple chronic venous } \\
\text { ulcers }\end{array}$ & 23.2 & 17.4 & n.s. & 23.5 & 17.8 & n.s. \\
\hline 01718 & $\begin{array}{l}\text { Well-child visit during the 46th to 48th month } \\
\text { of life "(U8)" }\end{array}$ & 13.8 & 2.5 & $<0.001$ & 12.2 & 1.2 & $<0.001$ \\
\hline 01719 & $\begin{array}{l}\text { Well-child visit during the 60th to 64th month } \\
\text { of life "(U9)" }\end{array}$ & 13.6 & 2.0 & $<0.001$ & 13.9 & 1.4 & $<0.001$ \\
\hline 02302 & $\begin{array}{l}\text { Minor surgery III: excisions, treatment } \\
\text { of ingrown toenails, phlebotomy }\end{array}$ & 13.0 & 2.0 & $<0.001$ & 12.1 & 2.1 & $<0.001$ \\
\hline 01723 & $\begin{array}{l}\text { Well-child visit during the 43rd to 36th month } \\
\text { of life "(U7a)" }\end{array}$ & 10.9 & 1.6 & $<0.001$ & 11.8 & 1.7 & $<0.001$ \\
\hline 01717 & $\begin{array}{l}\text { Well-child visit during the 21st to 24th month } \\
\text { of life "(U7)" }\end{array}$ & 10.6 & 0.9 & $<0.001$ & 10.2 & 1.0 & $<0.001$ \\
\hline 01716 & $\begin{array}{l}\text { Well-child visit during the 10th and 12th month } \\
\text { of life "(U6)" }\end{array}$ & 10.3 & 1.8 & $<0.001$ & 8.6 & 1.2 & $<0.001$ \\
\hline 01715 & $\begin{array}{l}\text { Well-child visit during the 6th and 8th month of } \\
\text { life "(U5)" }\end{array}$ & 8.3 & 1.3 & $<0.001$ & 8.2 & 1.2 & $<0.001$ \\
\hline 01714 & $\begin{array}{l}\text { Well-child visit during the } 3 \text { rd and } 4 \text { th month of } \\
\text { life "(U4)" }\end{array}$ & 8.1 & 1.1 & $<0.001$ & 7.1 & 1.2 & $<0.001$ \\
\hline 01713 & $\begin{array}{l}\text { Well-child visit during the 4th and 5th week of } \\
\text { life "(U3)" }\end{array}$ & 6.4 & 0.9 & $<0.001$ & 6.4 & 0.6 & $<0.001$ \\
\hline 02500 & Single inhalation therapy & 5.3 & 2.5 & n.s. & 4.9 & 2.3 & n.s. \\
\hline 03335 & $\begin{array}{l}\text { Exploratory audiometry after previously } \\
\text { documented, hearing test anomalies }\end{array}$ & 3.7 & 1.6 & n.s. & 3.1 & 0.8 & n.s. \\
\hline 01730 & Cancer screening for women & 3.2 & 0.0 & 0.010 & 1.8 & 0.0 & n.s. \\
\hline 01712 & $\begin{array}{l}\text { Well-child visit of the new-born during the } \\
3 \text { rd to 10th day of life }\end{array}$ & 2.5 & 0.0 & n.s. & 2.4 & 0.2 & n.s. \\
\hline
\end{tabular}

*Bonferroni correction

only procedures with percentages larger than $1.0 \%$ for at least one specialty are shown bold percentages indicate a significant difference between 2013 and 2015 (at the 5\% level) n.s. not significant (at the $5 \%$ level) 
Table 4 Application rates of general practitioners (GPs) and general internal medicine (GIM) physicians for procedures performed to a greater extent by GIM physicians (in \%)

\begin{tabular}{|c|c|c|c|c|c|c|c|}
\hline \multirow[t]{2}{*}{ Code } & \multirow[t]{2}{*}{ Description } & \multicolumn{3}{|l|}{2013} & \multicolumn{3}{|l|}{2015} \\
\hline & & $\mathrm{GP}(n=1228)$ & $\operatorname{GIM}(n=447)$ & $p$-value* & $\mathrm{GP}(n=1227)$ & $\operatorname{GIM}(n=484)$ & $p$-value* \\
\hline 03330 & Spirometry & 80.5 & 82.3 & n.s. & 80.1 & 83.7 & n.s. \\
\hline 03324 & 24-h ambulatory blood pressure monitoring & 72.2 & 82.8 & $<0.001$ & 74.2 & 82.9 & 0.011 \\
\hline 32040 & Faecal occult blood test in 3 samples & 68.5 & 70.0 & n.s. & 66.0 & 66.9 & n.s. \\
\hline 33042 & Abdominal sonography B-scan & 52.9 & 91.1 & $<0.001$ & 51.6 & 89.3 & $<0.001$ \\
\hline 03321 & Cardiac stress test & 45.5 & 79.6 & $<0.001$ & 52.6 & 82.4 & $<0.001$ \\
\hline 32031 & Microscopic urinalysis for morphological components & 37.8 & 41.6 & n.s. & 34.5 & 34.9 & n.s. \\
\hline 33012 & Thyroid sonography B-scan & 21.4 & 73.6 & $<0.001$ & 21.5 & 75.4 & $<0.001$ \\
\hline 02313 & $\begin{array}{l}\text { Compression therapy for chronic venous insufficiency, } \\
\text { post-thrombotic syndrome, superficial and deep vein } \\
\text { thrombosis and/or lymphoedema }\end{array}$ & 15.8 & 16.1 & n.s. & 20.7 & 19.8 & n.s. \\
\hline 03331 & Proctoscopy & 6.4 & 7.4 & n.s. & 5.2 & 7.2 & n.s. \\
\hline 02311 & Diabetic foot care & 6.2 & 10.1 & n.s. & 5.5 & 9.9 & n.s. \\
\hline 33061 & $\begin{array}{l}\text { CW Doppler sonography of limb blood vessels, at } \\
\text { least } 3 \text { transducer locations per limb }\end{array}$ & 1.6 & 8.5 & $<0.001$ & 1.5 & 7.2 & $<0.001$ \\
\hline 33060 & $\begin{array}{l}\text { Sonographic examination of extracranial cerebral vessels, } \\
\text { the periorbital arteries, subclavian arteries and vertebral } \\
\text { arteries by CW-Doppler }\end{array}$ & 1.1 & 3.6 & 0.036 & 1.1 & 3.3 & n.s. \\
\hline 01220 & Resuscitation & 0.7 & 1.1 & n.s. & 1.1 & 0.0 & n.s. \\
\hline 33076 & Limb vein B-scan sonography at least 8 transducer locations & 0.3 & 8.7 & $<0.001$ & 0.6 & 9.3 & $<0.001$ \\
\hline
\end{tabular}

*Bonferroni correction

only procedures with percentages larger than $1.0 \%$ for at least one specialty are shown

bold percentages indicate a significant difference between 2013 and 2015 (at the $5 \%$ level)

n.s. not significant (at the $5 \%$ level)

We analysed differences in patterns of procedures performed by German GPs and GMI physicians based on routine data collected by ASHIP for the federal state of Schleswig-Holstein over two distinct time periods in 2013 and 2015. In total, 1227 GPs and 484 GIM physicians were looked at in 2015. This cohort represented about $3.5 \%$ of all GPs and GIM physicians practising in Germany in 2015 [18]. The ratio of codes billed per specialty (GPs: $72 \%(73 \%)$ and GIM physicians: $28 \%$ (27\%) in 2015 (2013)) are nearly identical for both specialties and years to the respective nation-wide proportions of cases treated and codes billed in primary care [46, 47]. Furthermore, the differences over the time frame underline the rising significance of GIM physicians in the provision of primary care in Germany.

The results show substantial differences between GPs and GIM physicians in the application rates of most of the identified procedures. In general, procedures with higher application rates by GPs tend to be more advisory and concern the prevention of health problems. In contrast, procedures with higher application rates by GMI physicians are to a greater extent technically orientated. These results are consistent with findings of previous studies $[7,12,19]$.

In 2015 , for example, more than $25 \%$ of GPs performed health visits for adolescents. In contrast, less than $10 \%$ of GIM physicians performed this procedure. Well-child visits show similar differences. These figures reflect a wider range in the age of patients treated by GPs compared to GIM physicians. Health services for children are also provided by paediatricians [48]. In German rural areas, however, a shortage of paediatricians leads to children's healthcare services being delivered by GPs or GIM physicians [49]. Moreover, rural areas are particularly affected by the declining number of GPs. Therefore, GIM physicians stand a higher chance of accreditation in rural areas to counteract the shortage of GPs. Our results suggest that GMI physicians practising in rural areas need to get involved in children's and adolescents' healthcare services in order to safeguard a high quality of service provision.

Some of the procedures dealing with health screening of adults have also significantly higher application shares for GPs. This is in line with findings of previous studies, that GPs place more emphasis on preventive services [7, 12]. Recent studies highlight the positive effects of preventive care on the reduction of hospital admissions and emergency department visits [50-52]. In Germany, the increasing number of non-urgent emergency department visits has resulted in overstretched emergency facilities with negative effects on quality and effectiveness of the emergency care provision [53-55]. Especially in rural areas 
with relatively high proportions of elderly people [56] and limited public transport to gain access to primary healthcare provision [57] emergency departments tend to compensate for the lack of primary care physicians $[58,59]$. This study found that a significantly smaller percentage of GIM physicians provided preventive services. Therefore, an increase in the overall number of GIM physicians is likely to result in a decrease in the provision of preventive services. This points to a need for the inclusion of preventive medicine in the curriculum for the future training of GIM physicians and postgraduate training for GIM physicians, especially for those practising in rural areas.

Most of the procedures involving minor surgery show significantly higher application rates for GPs. Minor surgery is largely part of the vocational training scheme of GPs as opposed to the training of GIM physicians [45]. Advantages of providing minor surgery in a primary care setting include improved access to surgical care for patients, reduced waiting times and improved patient satisfaction [60]. Although evidence about the quality and cost effectiveness is mixed [61], there are international studies that suggest lower referral rates to secondary care if minor surgery procedures had been performed by GPs [62]. Furthermore, only small differences have been observed between the quality of minor surgery procedures carried out in primary and secondary care setting. In any case, patient satisfaction for minor surgery procedures performed in primary care has been higher [63]. The data show a slightly but insignificant increase over time of GIM physicians offering minor surgery procedures, resulting in a narrowing of the gap between both specialties. However, in order to boost this development, a reassessment of GIM physicians' vocational training programmes should focus on minor surgical procedures.

Similar to previous findings $[7,12,64]$ a more technical orientation of GIM physicians was observed in this study. Moreover, GIM physicians had significantly higher shares for procedures that, in Germany, are close to the specialty of internal medicine, e.g. ultrasound diagnostics, cardiac stress testing and 24-h blood pressure monitoring. This is not surprising due to the exclusive emphasis on internal medicine in the GIM physicians' training. A previous study showed that German GPs practising in rural areas perform a larger number of distinct procedures compared with GPs in urban areas [25], indicating that they may offset a lack of specialists. This is in line with the findings of Starfield et al. [11] that patients in the US who have a GP as their primary care physician see fewer specialists. The ability to perform a wider range of specialist procedures should be trained for both GPs and GIM physicians, especially for those who practise in rural areas.

In summary, our results suggest substantial differences in the application of procedures between GPs and GIM physicians with potential consequences for primary healthcare provision in general. Most of the differences correlate with differences in the training programmes. As only about $30 \%$ of the consultations in primary care practice relate to internal medicine [65], the findings could foster a discussion about training needs for procedures in primary care to ensure its comprehensiveness. The results reflect scope for changes in vocational training in the future. On the other hand, GIM physicians have the opportunity to train their procedural skills, e.g. by attending the educational seminars accompanying the post-graduate training for GPs. These seminars have been defined by the German College of General Practice and Family Physicians (DEGAM) as a core element to improve trainees' specific knowledge and competencies [66]. From the beginning, the trainees attend training courses preparing for the specific requirements of independent medical work, especially in rural regions.

Beyond training, economic incentives may also reduce the differences in the application of procedures between GPs and GIM physicians. In general, the use of financial incentives is considered to control the physician's behaviour $[67,68]$. Improving the billing options and financial rewards for specific procedures (e.g. preventive care or minor surgeries) might encourage primary care physicians to perform these procedures more often. The explicit effect of changes in the reimbursement on the application of procedures is an interesting issue for future research.

\section{Strengths and limitations}

The study highlights the difference in services provided by GPs and GIM physicians and provides suggestions about emphases for residency trainings and future efforts for an effective and efficient re-allocation of primary healthcare.

The study has strengths as well as limitations. A strength of this study is that it relies on routine data collected for all GPs and GIM physicians in a specific region of Germany. There are no issues related to any selection or response bias, as might be the case when survey data are used [20]. Social desirability bias might play a particular role when surveying physicians about their services. On the one hand, focusing on the federal state of Schleswig-Holstein constrains the representativeness of the findings, on the other hand, this reduces practice variations based on regional differences and state-specific regulations [28]. Furthermore, this study shows only unconditional differences between both specialties. The age, gender, experience and regional characteristics of the physician may also determine the probability of specific services being provided [25]. Moreover, we cannot control for the patient mix. Unfortunately, for Germany there is no evidence available 
about the differences in the patient mix between GPs and GIM physicians. In Germany, patients can freely choose their doctor. Although an increasing use of physician-rating websites can be observed $[69,70]$ most patients consult the nearest primary care physician [66]. For example, in the US, only half of the primary care patients know whether their doctor has been trained as a GP or GIM physician [67]. Therefore, we conclude that the specialty of the primary care physician does not have a strong effect on the patient's physician choice in Germany either. Moreover, the study considered differences between the percentages of physicians performing a specific procedure even when only performed once. This measure will be relatively robust against moderate differences in the patient mix. However, future studies analysing practice style patterns of GIM physicians and GPs should be based on a country-wide dataset and take into account regional and personal characteristics, as well as patient mix information.

Another limitation is that most of the procedures applied by GIM physicians and GPs are not directly represented by the schedule of service codes. This has resulted in a limited number of procedures that were analysed. Moreover, opportunistic practices to increase the reimbursement might lead to billing of services that are not actually performed. Another limitation is given by potential differences between GPs and GIM physicians in their knowledge about how to bill specific procedures. Since GIM physicians do not necessarily need to pass through training in private practices, they may have different awareness or prioritisation in regard to billing. However, in comparison with the use of survey data about procedures applied and the related problems mentioned above, these issues may be negligible.

A further limitation is that the ASHIP is in charge only for the reimbursement of services that are provided to patients within the statutory health insurance system. Services provided to privately insured patients are not covered by the underlying dataset. There are large differences between the service provision for privately and statutorily insured patients [71]. Since the dataset covers $85 \%$ of the population of Schleswig-Holstein [72], this is regarded as a minor limitation. However, the effect of the health insurance status on service provision may represent an interesting topic for future research.

\section{Conclusion}

This study shows substantial differences in the application of procedures between GPs and GIM physicians with potential consequences for the overall primary healthcare provision. Most of the differences are explainable with differences in the training programmes between both specialties. These findings could foster a discussion that primary care physicians should uniformly master relevant procedures in primary care and reflect scope for changes in vocational training in the future.

\section{Abbreviations}

ASHIP: Association of Statutory Health Insurance Physicians; DEGAM: German College of General Practice and Family Physicians; ECG: Electrocardiograms; GIM: Physicians in general internal medicine; GP: General practitioner

\section{Acknowledgements}

We would like to thank Uwe Köppen and Andrea Strathausen for proofreading the manuscript.

\section{Funding}

No external funding was used for this study.

\section{Availability of data and materials}

The data from this study are not available for public use, as the data are owned by the ASHIP and the authors are not allowed to share the data with third parties.

\section{Authors' contributions}

CS, KF and JS were involved in the conception and design of the study. KF assigned the procedures to the bill codes. TE extracted and cleaned the data. CS and KF carried out the statistical analysis. CS, KF and JS interpreted the data. CS produced the first draft of the manuscript. All authors contributed to and approved the final manuscript.

\section{Ethics approval and consent to participate}

The data stem from an administrative database and the data were anonymous. Ethical approval was not necessary for this study as the professional code of doctors states that the collection of anonymous data requires no ethical approval [73].

\section{Consent for publication}

Not applicable

\section{Competing interests}

JS is general practitioner; the other authors declare that they have no competing interests.

\section{Publisher's Note}

Springer Nature remains neutral with regard to jurisdictional claims in published maps and institutional affiliations.

\section{Author details}

${ }^{1}$ Institute of Family Medicine, University Hospital Schleswig-Holstein, Campus Luebeck, Ratzeburger Allee 160, 23538 Luebeck, Germany. ${ }^{2}$ Association of Statutory Health Insurance Physicians of the Federal State of Schleswig-Holstein, Bismarckallee 1-6, 23795 Bad Segeberg, Germany.

Received: 28 August 2018 Accepted: 19 November 2018 Published online: 03 December 2018

\section{References}

1. Dall T, West $T$, Chakrabarti $R$, lacobucci W. The complexities of physician supply and demand: projections from 2013 to 2025. Washington: Association of American Medical Colleges; 2015.

2. Kaduszkiewicz $H$, Teichert $U$. Shortage of physicians in rural areas and in the public health service: a critical analysis of the evidence on the role of medical education and training. Bundesgesundheitsblatt, Gesundheitsforschung, Gesundheitsschutz 2017.

3. Petterson SM, Liaw WR, Tran C, Bazemore AW. Estimating the residency expansion required to avoid projected primary care physician shortages by 2035. Ann Fam Med. 2015:13(2):107-14.

4. American Academy of Family Physicians. Definition \#3 - Primary Care Physician. https://www.aafp.org/about/policies/all/primary-care.html\#3. (Accessed 19 Nov 2018).

5. Chan BT. The declining comprehensiveness of primary care. Can Med Assoc J. 2002;166(4):429-34. 
6. Shackelton-Piccolo R, McKinlay JB, Marceau LD, Goroll AH, Link CL. Differences between internists and family practitioners in the diagnosis and management of the same patient with coronary heart disease. Med Care Res Rev. 2011;68(6):650-66.

7. Bertakis KD, Helms LJ, Azari R, Callahan EJ, Robbins JA, Miller J. Differences between family physicians' and general internists' medical charges. Med Care. 1999;37(1):78-82.

8. Brieler JA, Scherrer JF, Salas J. Differences in prescribing patterns for anxiety and depression between general internal medicine and family medicine. J Affect Disord. 2015;172:153-8.

9. Paasche-Orlow M, Roter D. The communication patterns of internal medicine and family practice physicians. J Am Board Fam Pract. 2003;16(6): 485-93.

10. Wiest FC, Ferris TG, Gokhale M, Campbell EG, Weissman JS, Blumenthal D. Preparedness of internal medicine and family practice residents for treating common conditions. JAMA. 2002;288(20):2609-14.

11. Starfield B, Chang H-Y, Lemke KW, Weiner JP. Ambulatory specialist use by nonhospitalized patients in US health plans: correlates and consequences. J Ambul Care Manage. 2009;32(3):216-25.

12. Bertakis KD, Callahan EJ, Helms $\sqcup$, Azari R, Robbins JA, Miller J. Physician practice styles and patient outcomes: differences between family practice and general internal medicine. Med Care. 1998;36(6):879-91.

13. Grobe TG, Steinmann S, Szecsenyi J. Arztreport 2018 - Schriftenreihe zur Gesundheitsanalyse Bd 7: Barmer GEK, Berlin; 2018.

14. Busse R, Blümel M, Knieps F, Bärnighausen T. Statutory health insurance in Germany: a health system shaped by 135 years of solidarity, self-governance, and competition. Lancet. 2017;390(10097):882-97.

15. Sozialgesetzbuch (SGB V), Fünftes Buch. Gesetzliche Krankenversicherung. https://www.sozialgesetzbuch-sgb.de/sgbv/73.html (Accessed 19 Nov 2018).

16. Steinhäuser J, Scheidt L, Szecsenyi J, Götz K, Joos S. Perceptions of the local government about the primary care physicians shortage-a survey among mayors in the Federal State of Baden-Wuerttemberg. Gesundheitswesen. 2012;74(10):612-7

17. Kopetsch T. The German healthcare system is running out of physicians! A study on age structure and development of the number of physicians. Berlin: Bundesärztekammer und Kassenärztliche Bundesvereinigung; 2010.

18. Association of Statutory Health Insurance Physicians. Statistical information from the federal physician registry. Berlin: KBV; 2017.

19. Jaekel K, Brand B, Goetz K, Steinhaeuser J: Which procedures are performed by primary care physicians? - a comparison of specialists in family medicine and general internal medicine. In: WONCA Europe Conference 2016. Copenhagen, Denmark; 2016 (Conference Talk).

20. Davino C, Fabbris L: Survey data collection and integration: Springer; 2013.

21. Abadel FT, Hattab AS. How does the medical graduates' self-assessment of their clinical competency differ from experts' assessment? BMC Med Educ. 2013;13(1):24.

22. Colbert-Getz JM, Fleishman C, Jung J, Shilkofski N. How do gender and anxiety affect students' self-assessment and actual performance on a highstakes clinical skills examination? Acad Med. 2013;88(1):44-8.

23. Minter RM, Gruppen LD, Napolitano KS, Gauger PG. Gender differences in the self-assessment of surgical residents. Am J Surg. 2005;189(6):647-50.

24. Coughlin SS. Recall bias in epidemiologic studies. J Clin Epidemiol. 1990; 43(1):87-91.

25. Steinhäuser J, Jäkel K, Szecsenyi J, Goetz K, Ledig T, Joos S. Procedures performed in general practice-a cross-sectional study. Gesundheitswesen. 2016.

26. Ohlmeier C, Frick J, Prütz F, Lampert T, Ziese T, Mikolajczyk R, Garbe E. Use of routine data from statutory health insurances for federal health monitoring purposes. Bundesgesundheitsblatt, Gesundheitsforschung, Gesundheitsschutz. 2014;57(4):464-72.

27. Powell AE, Davies HTO, Thomson RG. Using routine comparative data to assess the quality of health care: understanding and avoiding common pitfalls. BMJ Qual Saf. 2003;12(2):122-8.

28. Corallo AN, Croxford R, Goodman DC, Bryan EL, Srivastava D, Stukel TA. A systematic review of medical practice variation in OECD countries. Health Policy. 2014;114(1):5-14.

29. Kassenärztliche Bundesvereinigung: Einheitlicher Bewertungsmaßstab (EBM). http://www.kbv.de/html/online-ebm.php (Accessed 19 Nov 2018).

30. Kelly BF, Sicilia JM, Forman S, Ellert W, Nothnagle M. Advanced procedural training in family medicine: a group consensus statement. Fam Med. 2009; 41(6):398-404.
31. Sylvester S, Magin P, Sweeney K, Morgan S, Henderson K. Procedural skills in general practice vocational training: what should be taught? Aust Fam Physician. 2011;40(1/2):50.

32. Steinhaeuser J, Chenot J-F, Roos M, Ledig T, Joos S. Competence-based curriculum development for general practice in Germany: a stepwise peerbased approach instead of reinventing the wheel. BMC Res Notes. 2013;6(1): 314.

33. Wickstrom GC, Kelley DK, Keyserling TC, Kolar MM, Dixon JG, Xie SX, Lewis $C L$, Bognar BA, DuPre CT, Coxe DR, et al. Confidence of academic general internists and family physicians to teach ambulatory procedures. J Gen Intern Med. 2000;15(6):353-60.

34. Goeman JJ, Solari A. Multiple hypothesis testing in genomics. Stat Med. 2014;33(11):1946-78

35. Van Lerberghe $W$. The world health report 2008: primary health care now more than ever. Geneva: World Health Organization; 2008.

36. Gottschalk A, Flocke SA. Time spent in face-to-face patient care and work outside the examination room. Ann Fam Med. 2005:3(6):488-93.

37. Bodenheimer T. Coordinating care-a perilous journey through the health care system. N Engl J Med. 2009;358(10):1064-71.

38. Starfield B, Shi L, Macinko J. Contribution of primary care to health systems and health. Milbank Q. 2005:83(3):457-502.

39. Shi L, Starfield B, Politzer R, Regan J. Primary care, self-rated health, and reductions in social disparities in health. Health Serv Res. 2002;37(3):529-50.

40. Lee A, Kiyu A, Milman HM, Jimenez J. Improving health and building human capital through an effective primary care system. J Urban Health. 2007;84(1):75-85.

41. Kringos DS, Boerma WG, Hutchinson A, van der Zee J, Groenewegen PP. The breadth of primary care: a systematic literature review of its core dimensions. BMC Health Serv Res. 2010;10(1):65.

42. Bazemore A, Petterson S, Peterson LE, Phillips RL. More comprehensive care among family physicians is associated with lower costs and fewer hospitalizations. Ann Fam Med. 2015;13(3):206-13.

43. Pavlič DR, Sever M, Klemenc-Ketiš Z, Švab I, Vainieri M, Seghieri C, Maksuti A Strength of primary care service delivery: a comparative study of European countries, Australia, New Zealand, and Canada. Prim Health Care Res Dev. 2018;19(3):277-87

44. Martin JCAR, Bowman MA, Bucholtz JR, Dickinson JR, Evans KL, Green LA, Henley DE, Jones WA, Matheny SC, Nevin JE, Panther SL, Puffer JC, Roberts RG, Rodgers DV, Sherwood RA, Stange KC, Weber CW. Future of family medicine project leadership committee: the future of family medicine: a collaborative project of the family medicine community. Ann Fam Med. 2004;2(suppl 1):S3-S32.

45. Ärztekammer Schleswig-Holstein: Weiterbildungsordnung. https://www. aeksh.de/system/files/documents/wbo_2011-05-25_idf_2017-04-19.pdf (Accessed 19 Nov 2018).

46. Grobe TG, Steinmann S, Szecsenyi J. Arztreport 2017 - Schriftenreihe zur Gesundheitsanalyse, Bd 1. Berlin: Barmer GEK; 2017.

47. Grobe TG, Klingenberg A, Steinmann S, Szecsenyi J. Arztreport 2015 Schriftenreihe zur Gesundheitsanalyse, Bd. 30. Berlin: Barmer GEK; 2015.

48. Straßburg H-M: Herkömmliche und neue U-Untersuchungen beim Kleinkind In: Kindergesundheit stärken: Vorschläge zur Optimierung von Prävention und Versorgung. edn. Bitzer EM, Walter U, Lingner $\mathrm{H}$, Schwartz F-W. Berlin, Heidelberg: Springer Berlin Heidelberg; 2009: 91-99.

49. van den Berg N, Seidlitz G, Meinke-Franze C, Pieper C, Lode H, Hoffmann W: Auswirkungen des demografischen Wandels auf die kinder-und jugendmedizinische Versorgung in der Region Ostvorpommern. In: Think Rural! , Edn. Edited by Dünkel F, Herbst M, Schlegel T. Germany: Springer; 2014: 65-72.

50. Emery J $\mathrm{CH}$, Zheng $X$. Would better access to preventive care reduce use of acute care? Evidence from a large-scale not-for-profit intervention in Alberta. Can Public Policy. 2018:44(1):13-24.

51. Herwartz H, Klein N, Strumann C. Modelling hospital admission and length of stay by means of generalised count data models. J Appl Econ. 2016;31(6): 1159-82.

52. Büyükdurmus $T$, Kopetsch $T$, Schmitz $H$, Tauchmann $H$. On the interdependence of ambulatory and hospital care in the German health system. Health Econ Rev. 2017;7(1):2.

53. Carter EJ, Pouch SM, Larson EL. The relationship between emergency department crowding and patient outcomes: a systematic review. J Nurs Scholarsh. 2014:46(2):106-15.

54. Bernstein SL, Aronsky D, Duseja R, Epstein S, Handel D, Hwang U, McCarthy M, John McConnell K, Pines JM, Rathlev N, et al. The effect of emergency 
department crowding on clinically oriented outcomes. Acad Emerg Med. 2009;16(1):1-10.

55. Johnson KD, Winkelman C. The effect of emergency department crowding on patient outcomes: a literature review. Adv Emerg Nurs J. 2011;33(1):39-54.

56. Haustein T, Mischke J, Schönfeeld F, Willand I. Ältere Menschen in Deutschland und der EU: Statistisches Bundesamt; 2016.

57. Stentzel U, Piegsa J, Fredrich D, Hoffmann W, Berg N. Accessibility of general practitioners and selected specialist physicians by car and by public transport in a rural region of Germany. BMC Health Serv Res. 2016;16(1):587.

58. Mathison DJ, Chamberlain JM, Cowan NM, Engstrom RN, Fu LY, Shoo A, Teach SJ. Primary care spatial density and nonurgent emergency department utilization: a new methodology for evaluating access to care. Acad Pediatr. 2013;13(3):278-85.

59. Fishman J, McLafferty S, Galanter W. Does spatial access to primary care affect emergency department utilization for nonemergent conditions? Health Serv Res. 2018;53(1):489-508.

60. Collins AM, Ridgway PF, Hassan MS, Chou CW, Hill AD, Kneafsey B. Surgical instruction for general practitioners: how, who and how often? J Plast Reconstr Aesthet Surg. 2010;63(7):1156-62.

61. Taneja A, Singh PP, Tan JP, Hill DG, Connolly AB, Hill AG. Efficacy of general practitioners with specialty interests for surgical procedures. ANZ I Surg. 2015;85(5):344-8.

62. van Dijk CE, Verheij RA, Spreeuwenberg P, Groenewegen PP, de Bakker DH. Minor surgery in general practice and effects on referrals to hospital care: observational study. BMC Health Serv Res. 2011;11(1):2.

63. George S, Pockney P, Primrose J, Smith H, Little P, Kinley H, Kneebone R, Lowy A, Leppard B, Jayatilleke N: A prospective randomised comparison of minor surgery in primary and secondary care. The MiSTIC trial. Technical Report Tunbridge Wells, Kent: Gray Publishing; 2008.

64. Bertakis KD, Robbins JA, Callahan EJ, Helms LJ, Azari R. Physician practice style patterns with established patients: determinants and differences between family practice and general internal medicine residents. Fam Med. 1999;31:187-94.

65. Steinhäuser J. Inhaltliche Verbesserung weiterbildungsbegleitender Lerngruppen durch Daten des CONTENT-Projekts. In: Laux G, Kühlein T, Gutscher A, Szecsenyi J, editors. Versorgungsforschung in der Hausarztpraxis. edn. München: Urban und Vogel; 2010. p. 76-9.

66. Flum E, Magez J, Aluttis F, Hoffmann M, Joos S, Ledig T, Oeljeklaus L, Simon M, Szecsenyi J, Steinhäuser J. Das Schulungsprogramm der Verbundweiterbildungplus Baden-Württemberg: Entwicklung und Implikationen für die Implementierung von Verbundweiterbildungsprogrammen in Deutschland. Zeitschrift für Evidenz, Fortbildung und Qualität im Gesundheitswesen. 2016;112:54-60.

67. Town R, Kane R, Johnson P, Butler M. Economic incentives and physicians' delivery of preventive care: a systematic review. Am J Prev Med. 2005;28(2): $234-40$

68. Armour BS, Pitts M, Maclean R, et al. The effect of explicit financial incentives on physician behavior. Arch Intern Med. 2001;161(10):1261-6.

69. Rothenfluh F, Schulz PJ. Content, quality, and assessment tools of physicianrating websites in 12 countries: quantitative analysis. J Med Internet Res. 2018;20(6):e212.

70. Emmert M, Hessemer S, Meszmer N, Sander U. Do German hospital report cards have the potential to improve the quality of care? Health Policy. 2014; 118(3):386-95.

71. Lüngen M, Gerber A, Stollenwerk B, Lauterbach KW. Ungleichheit der medizinischen Versorgung in Deutschland. Eine empirische Untersuchung in Hochschulambulanzen Z Sozialreform. 2005, 51(3):298-314.

72. Zentralinstitut für die kassenärztliche Versorgung in Deutschland (Zl): Zahl der Versicherten in der GKV gemäß KM6 - Statistiken des Bundesministeriums für Gesundheit (BMG). https://www.versorgungsatlas. de/fileadmin/pdf/Zi-IF Publ-D\%C3\%84 vTabelle1 V5_20160609.pdf (Accessed 19 Nov 2018).

73. Ärztekammer Schleswig-Holstein: Berufsordnung. https://www.aeksh.de/ system/files/documents/berufsordnung_final_3.pdf (Accessed 19 Nov 2018).

Ready to submit your research? Choose BMC and benefit from:

- fast, convenient online submission

- thorough peer review by experienced researchers in your field

- rapid publication on acceptance

- support for research data, including large and complex data types

- gold Open Access which fosters wider collaboration and increased citations

- maximum visibility for your research: over $100 \mathrm{M}$ website views per year

At BMC, research is always in progress.

Learn more biomedcentral.com/submissions 